\title{
INSIGHTS INTO KINETICS OF MAGNESIUM REMOVAL BY TITIAN YELLOW SUPPORTED ON CLASSIC THIOUREA-FORMALDEHYDE RESIN
}

\author{
Khalid Z. Elwakeel \\ University of Jeddah, College of Science, Department of Chemistry, Jeddah, Saudi Arabia \\ Environmental Science Department, Faculty of Science, Port-Said University, Port-Said, Egypt \\ E-mail:kelwkeel@uj.edu.sa; khalid_elwakeel@sci.psu.edu.eg
}

\begin{abstract}
It was evaluated for the adsorption behavior and the underlying kinetics of magnesium sorption on Titian yellow (TY) supported on thiourea-formaldehyde resin (TF). The results of analyzing sorption behavior showed that the sorption environment had different effects on the sorption of $\mathrm{Mg}$ (II) ions. It could be found that $\mathrm{pH}$ had the best sorption effect on $\mathrm{Mg}(\mathrm{II})$ ions, The maximum adsorption capacity of $\mathrm{Mg}$ was $19.45 \mathrm{mg} \mathrm{g}^{-1}$ when it was at initial $\mathrm{pH}=10.5$. Under the optimal conditions, the maximum sorption capacities of $\mathrm{Mg}$ (II) ions was $19.45 \mathrm{mg} \mathrm{g}^{-1}$. Therefore, TF-TY was found to be a most efficient adsorbent for $\mathrm{Mg}(\mathrm{II})$ removal from water.
\end{abstract}

Keywords: Adsorption; $\operatorname{Mg}(\mathrm{II})$ ions; Titian yellow; Kinetic.

\section{INTRODUCTION}

People cannot live without water. Water is the source of life and an important component of sustainable economic and social development. The need for drinking water quality standards require continuous upgrading of water purification technology. Presence of hardness ions in the municipal drinking water is the major health concern. Water hardness can be attributed to the presence of certain ions in water which can easily form undissolved salts (Teixeira et al., 2012). Some of the common ions include

calcium ions, magnesium ions, ferrous ions, manganese ions and aluminum ions. Treatment processes often include the removal of these ions due to certain water quality requirements (Apell and Boyer, 2010).So to minimize the hardness of drinking water up to the environmental protection authority (EPA) quality standard expensive treatments are available. However, in actual water bodies, cationic hardness substances are often widespread. Less than one percent of fresh water is accessible from ground level for human consumption (Harper et al., 2017). In some cases, the resource does not satisfy to the desirable levels regarding their chemical properties (composition), such as hardness, nitrate contamination, heavy metals, soluble iron, etc (Hailu et al., 2019). From that undesirable chemical that most groundwater source has; water hardness is the dominant one and major challenge for most of the water supply system (Dunlap and Mertig, 2014). In general, water supplies with total hardness higher than $200 \mathrm{mg} \mathrm{L}^{-1}$ can be tolerated but considered to be poor resources; while values higher than $300 \mathrm{mg} \mathrm{L}^{-1}$ are not acceptable for most of the domestic consumptions (Hounslow, 2018). An existence of the calcium, magnesium and carbonate ions on the earth layer influences the hydrochemistry of groundwater (Tirkey et al., 2017). Hardness of water is due to moisture and carbon dioxide reacts with calcium and magnesium ion present on the earth surface (Boyd et al., 2016). The degree of hardness has been categories in temporary and permanent; temporary hardness can be reduced by boiling, but permanent hardness required specific treatment (MacAdam and Jarvis). Drinking highly hardness water for a long time can cause cardiovascular, nervous, urinary (Gibb et al., 2018, Zhi and Zhang, 2014) and hematopoietic diseases (Comstock and Boyer, 2014). Therefore, it is necessary to carry out studies develop a new method for removal of water hardness. Water treatment methods mainly include coagulation and flocculation, precipitation, chemical oxidation, membrane 
separation and adsorption (Rafatullah et al., 2010). Among them, adsorption technology is widely used because of its easy handling, low cost and high efficiency. Adsorption is considered as an valid method for balanced separation and water purification applications (Harikishore et al., 2017).

In recent years, domestic and foreign scholars have begun to look for new efficient and cheap adsorbent materials for magnesium sorption. This paper intended to use as a new material to study the adsorption behavior of $\mathrm{Mg}(\mathrm{II})$ ions. Firstly, the factors affecting the adsorption effect were investigated, and then the adsorption process was optimized by analyzing various parameters of adsorption kinetics. The purpose of this study was to explore the adsorption efficiency and kinetics of $\mathrm{Mg}(\mathrm{II})$ adsorption onto TF-TY adsorbent.

\section{MATERIAL AND METHODS}

\subsection{Chemicals}

Thiourea, formaldehyde solution (solution $37 \%$ w/w), Ferric chloride and ferrous sulphate were supplied by Sigma-Aldrich (Germany) as analytical grade reagents. Titan yellow (Thiazole Yellow G) was supplied from Lobal Chemie (India).

\subsection{Preparation of the sorbent}

$15.2 \mathrm{~g}(0.2 \mathrm{~mol})$ of thiourea and $40 \mathrm{~mL}$ of distilled water were mixed in a $250 \mathrm{~mL}$ round flask equipped with a stirrer and condenser. The solution was heated until completed dissolution of thiourea. Then, $0.2 \mathrm{~mol}$ of formaldehyde ( $15 \mathrm{~mL}$ of $37 \%$ aqueous solution) was added to the flask, $\mathrm{pH}$ adjustment was made by using $2 \mathrm{~mL}$ of glacial acetic acid. The reaction was continued for approximately $4 \mathrm{~h}$ with heating $(368 \mathrm{~K})$ and stirring. The obtained white product was washed with ultrapure water from a Milli-Q system (Millipore, Billerica, MA). The produced polymer was dried for $600 \mathrm{~min}$ at $323 \mathrm{~K}$ and denoted as TF.

\section{Titian yellow loading procedure}

Known amounts of dry TF beads were put in contact with known amounts (volume-concentration) of TY dye at $\mathrm{pH} 3$ at $25^{\circ} \mathrm{C}$ for $3 \mathrm{~h}$. Later on, the residual concentration of TY was measured by using a uv-vis spectrophotometer (T70+ UV/VIS spectrophotometer, PG instruments Ltd, UK) at maximum wavelengths of TY $(400 \mathrm{~nm})$.

\subsection{Batch sorption experiment}

Batch adsorption studies were conducted by adding equal amounts of TF-TY $(0.05 \mathrm{~g})$ to a series of identical plastic bottles equipped with $20 \mathrm{~mL} \mathrm{Mg(II)}$ ions solutions (20-200 $\mathrm{mg} \mathrm{L}^{-1}$ ) under a shaking incubator (LSI-3016R), at a certain temperature $(298 \mathrm{~K})$ to achieve equilibrium of the solution for 24 $\mathrm{h}$, then shaken at $150 \mathrm{rpm}$. The sample was extracted from the solution at appropriate intervals. The solution obtained by filtering through filter paper (Whatman, diam. $47 \mathrm{~mm}$ ). The equilibrium adsorption capacity of $\mathrm{Mg}$ (II) and the removal efficiency of $\mathrm{Mg}$ (II) on TF-TY were obtained by the following equations, respectively.

$q_{e}=\frac{\left(C_{0}-C_{e}\right) \times V}{m}$

Where $\mathrm{C}_{0}$ and $\mathrm{C}_{\mathrm{e}}\left(\mathrm{mg} \mathrm{L}^{-1}\right)$ are the concentrations of $\mathrm{Mg}$ (II) in the liquid phase at initial and equilibrium, respectively. V (L) is the volume of the solution and $\mathrm{W}(\mathrm{g})$ is the mass of adsorbent used.

\subsection{Effect of solution $\mathrm{pH}$}

The effect of $\mathrm{pH}$ on adsorption was studied by adsorption studies under different $\mathrm{pH}$ conditions. The initial concentration of $20 \mathrm{~mL} \mathrm{Mg}$ (II) solution was set to $20 \mathrm{mg} \mathrm{L}^{-1}$, adjusted to different $\mathrm{pH}$ values 
( $\mathrm{pH}$ 2-11), and $0.05 \mathrm{~g}$ of TF-TY was added. The $\mathrm{pH}$ was measured by using a $\mathrm{pH}$ meter (HANNA 211, China). Then, it was placed in a constant temperature shaking incubator and controlled the temperature. After shaking for $24 \mathrm{~h}$, the sample was taken out and the amount of adsorption at this time was measured.

\subsection{Kinetics studies}

For kinetic experiment, $100 \mathrm{~mL} \mathrm{Mg(II)} \mathrm{solutions} \mathrm{of} 20 \mathrm{mg} \mathrm{L}^{-1}$ initial concentration was shaken for different time interval with $0.1 \mathrm{~g}$ of TF-TY sorbent, and then the samples were taken and analyzed. Different kinetic models were used to study the rate control mechanism of $\mathrm{Mg}$ (II) ions adsorption onto TF-TY.

\section{RESULTS AND DISCUSSIONS}

\subsection{Charachtrization of TF-TY}

The FTIR spectra of different TF-TY were listed in Fig. 1. The FTIR spectra obtained showed that the functional groups of TF-TY. The peaks could be explained as follows: 3315 strong absorption peak indicates the presence of N-H of secondary amino group; $1625 \mathrm{~cm}^{-1}$ and 1156 are the distinguished peaks of $\mathrm{C}=\mathrm{S}$ - N- bond of thiourea moiety; $1551 \mathrm{~cm}^{-1}$ is $\mathrm{C}=\mathrm{NH}$ peak; $1425 \mathrm{~cm}^{-1}$ and 1330 are the peaks of $\mathrm{C}-\mathrm{N} ; 960 \mathrm{~cm}^{-1}$ confirmed the presence of thioether bonds S-C.
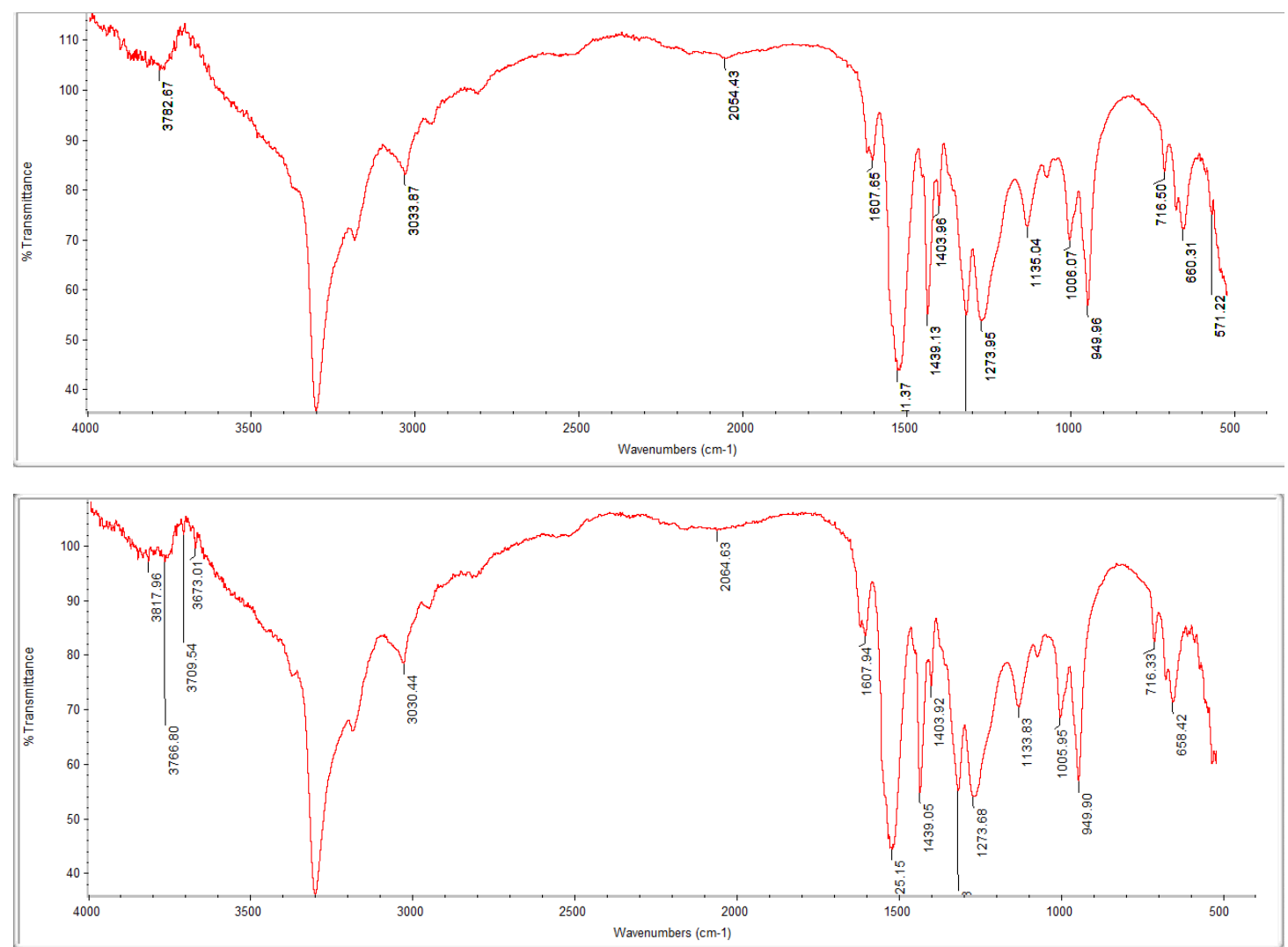

Fig. 1. FTIR spectra of TF and TF-TY. 


\subsection{Effect of pH}

The effect of the $\mathrm{pH}$ of the medium on the uptake was studied and the results are shown in Fig. 2. The highest uptake values were recorded at slightly alkaline $\mathrm{pH}$ of the $\mathrm{Mg}(\mathrm{II})$ ion solution. This may be attributed to the presence of free lone pair of electrons on nitrogen atoms as well as the presence of $\mathrm{SO}_{3}{ }^{-}$groups suitable for coordination with $\mathrm{Mg}(\mathrm{II})$ ions to give the corresponding resin-metal complex.

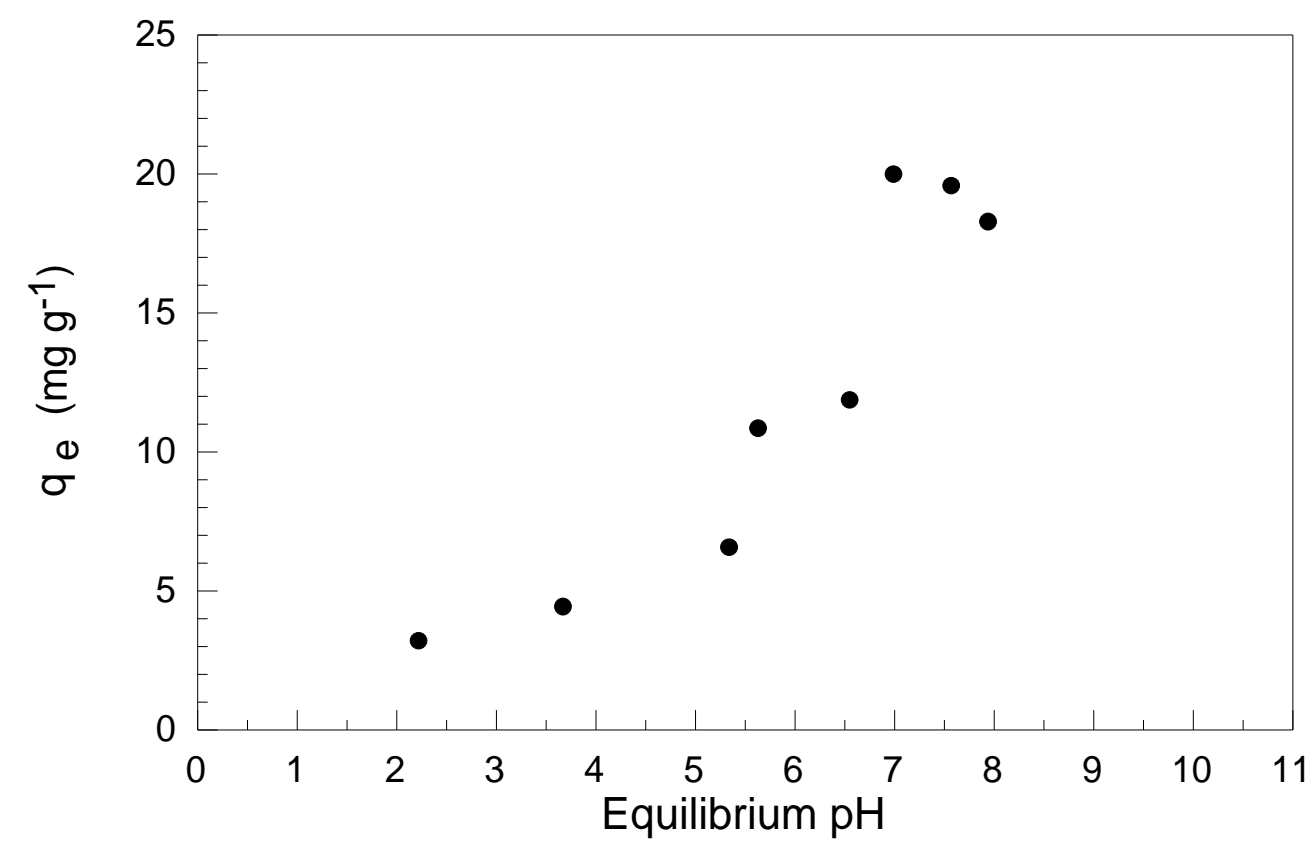

Fig. 2. (a) Effect of $\mathrm{pH}$ on $\mathrm{Mg}(\mathrm{II})$ sorption by TF-TY. (b) The $\mathrm{pH}$ values change of the mixed solution of TF-TY with $\mathrm{Mg}$ (II) after equilibration. (T=298 K, $\mathrm{C}_{0}=20 \mathrm{mg} \mathrm{L}^{-1}, \mathrm{~W}=0.05 \mathrm{~g}, \mathrm{~V}=20 \mathrm{~mL}$ )

\subsection{Effects of contact time}

The effects of contact time on the adsorption of Mg(II) ions by TF-TY were studied. It could be seen from Fig. 3 that the adsorption amount of $M g$ (II) by TF-TY increased with time. The adsorption results of the TF-TY showed that the amount of $\mathrm{Mg}$ (II) ions adsorbed to TF-TY increased rapidly with time at the beginning of the reaction, and then the amount of adsorption changed slowly and gradually stabilized. It was because there were a large number of empty positions on the surface of the TF-TY for adsorption in the initial stage, and when the reaction was in process, the remaining empty surface position becomes more and more difficult to occupy due to the repulsive force between the solute molecules. The results showed that the rate of $\mathrm{Mg}(\mathrm{II})$ adsorption was fast. This phenomenon was related to the mass transfer driving force. It should be due to the electrostatic attraction between TF-TY and $\mathrm{Mg}(\mathrm{II})$ ions.

\subsection{Kinetic analysis}

Comparison of MB adsorption characteristics based on adsorption studies on TF-TY particles at different times. In order to understand the kinetics of $\mathrm{Mg}(\mathrm{II})$ adsorption in TF-TY, four models including pseudo first order rate equation (PFORE) (Lagergren, 1898), pseudo second order rate equation (PSORE) (Ho and McKay, 1999), Weber and Morris model (W\&M) (Weber and Morris, 1963) and Elovich model (Zeldowitsch, 1934) were used. These model equations are reported in Table 1. 
Table 1: Kinetics models

\begin{tabular}{|c|c|c|}
\hline Kinetic model & Equation & References \\
\hline Pseudo-First order & $\mathrm{q}_{\mathrm{t}}=\mathrm{q}_{\mathrm{e}}\left[1-\mathrm{e}^{-\mathrm{k}_{1} \mathrm{t}}\right]$ & Lagergren, 1898 \\
\hline Pseudo-Second order & $\mathrm{q}_{\mathrm{t}}=\frac{\mathrm{k}_{2} \mathrm{t}}{1+\mathrm{k}_{2} \mathrm{q}_{\mathrm{e}} \mathrm{t}}$ & Ho and McKay, 1999 \\
\hline Intraparticle diffusion & $\mathrm{q}_{\mathrm{t}}=\mathrm{k}_{\mathrm{i}} \mathrm{t}^{0.5}+\mathrm{X}$ & Weber and Morris, 1963 \\
\hline Elovich equation & $\frac{\mathrm{dq}_{\mathrm{t}}}{\mathrm{dt}}=\alpha \mathrm{e}^{-\beta \mathrm{q}}$ & Zeldowitsch, 1934 \\
\hline \multicolumn{3}{|c|}{$\begin{array}{l}\mathrm{q}_{\mathrm{t}}\left(\mathrm{mg} \mathrm{g}^{-1}\right): \text { amount of dye sorbed at time }(\mathrm{t}) \\
\mathrm{q}_{\mathrm{e}}\left(\mathrm{mg} \mathrm{g}^{-1}\right): \text { equilibrium sorption. } \\
\mathrm{K}_{1}\left(\mathrm{~L} \mathrm{mg}^{-1}\right): \text { pseudo first -order rate constant of adsorption. } \\
\mathrm{K}_{2}\left(\mathrm{~g} \mathrm{mg}^{-1} \mathrm{~min}^{-1}\right): \text { pseudo second-order rate constant of adsorption. } \\
\mathrm{K}_{\mathrm{i}}\left(\mathrm{mg} \mathrm{g}^{-1} \mathrm{~min}^{-0.5}\right) \text { : the intra-particle diffusion rate. } \\
\mathrm{X}\left(\mathrm{mg} \mathrm{g}^{-1}\right): \mathrm{the} \text { boundary layer diffusion effects (external film resistance) } \\
\alpha\left(\mathrm{mg} \mathrm{g}^{-1} \mathrm{~min}^{-1}\right) \text { : the initial sorption rate. } \\
\beta\left(\mathrm{g} \mathrm{mg}^{-1}\right): \text { the desorption constant. }\end{array}$} \\
\hline
\end{tabular}

Table 2 illustrated the sorption kinetics data of $\mathrm{Mg}(\mathrm{II})$ onto the studied TF-TY at normal sorption conditions. The pseudo-first-order and pseudo-second-order models were used to represent singlenuclear and dual-nuclear adsorption processes in solid solution systems, respectively (Chen et al., 2018). The linear form of pseudo-first-order equation is expressed in the form:

$\ln \left(q_{e}-q_{t}\right)=\ln q_{e}-k_{1} t$

where $\mathrm{q}_{\mathrm{e}}$ is the equilibrium adsorption capacity $\left(\mathrm{mg} \mathrm{g}^{-1}\right), \mathrm{k}_{1}$ is the pseudo-first-order kinetic rate constant, $\mathrm{t}$ is the adsorption time ( $\mathrm{min})$ and $\mathrm{q}_{\mathrm{t}}$ is the adsorption capacity at $\mathrm{t}$ time $\left(\mathrm{mg} \mathrm{g}^{-1}\right)$. The pseudofirst-order kinetic equation was obtained by drawing the linear plots of $\ln \left(\mathrm{q}_{\mathrm{e}}-\mathrm{q}_{\mathrm{t}}\right)$ versus $\mathrm{t}$ (Fig. 4 (a)). the corresponding parameters were listed in Table 2. It could obtain from Table 2 that the correlation coefficient values of pseudo-first-order obtained were relatively small. This indicated that the adsorption of $\mathrm{Mg}$ (II) ions onto the TF-TY is not belong to pseudo-first-order equation. The pseudosecond-order dynamic equations can be expressed in the following form:

$\frac{t}{q_{t}}=\frac{1}{k_{2} q_{e}^{2}}+\left(\frac{1}{q_{e}}\right) t$

where $\mathrm{k}_{2}\left(\mathrm{~g} \mathrm{mg}^{-1} \mathrm{~min}^{-1}\right)$ is the rate constant of the pseudo-second-order reaction, and can be obtained through the slope and intercept of plot $\mathrm{t} / \mathrm{q}_{\mathrm{t}}$ against $\mathrm{t}$ (Fig. 4 (b)).

It could be seen from Fig. 4 (a) (b) that the pseudo-first-order kinetic adsorption data slightly deviated from the fitting curve, and the correlation coefficient $\mathrm{R}^{2}$ was 0.9428 . The fitting effect of the pseudosecond-order kinetic equation was relatively good, and the adsorption data was basically consistent with the fitting curve. $\mathrm{R}^{2}$ was 0.9993 . This phenomenon indicated that the adsorption mechanism of TF-TY to MB solution was diverse but it was still based on chemistry (Smith et al., 2016). The pseudo-second-order kinetic model provides a better fit than the pseudo-first-order model, suggesting that $\mathrm{Mg}$ (II) adsorption to TF-TY might involve multi-nucleus rather than single-nucleus adsorption process. Similar phenomena were reported for $\mathrm{As}(\mathrm{V})$ adsorption onto poly p-phenylenediamine- 
Table 2: Kinetic parameters for $\mathrm{Mg}(\mathrm{II})$ adsorption

\begin{tabular}{|c|c|c|c|c|c|c|c|c|c|c|c|}
\hline \multicolumn{3}{|c|}{ PFORE } & \multicolumn{3}{|c|}{ PSORE } & \multicolumn{3}{|c|}{ Weber and Morris model } & \multicolumn{3}{|c|}{ Elovich equation } \\
\hline $\begin{array}{l}\mathrm{k}_{1} \\
\text { (a) }\end{array}$ & $\begin{array}{l}\mathrm{q}_{\mathrm{e}, \text { calc }} \\
\text { (b) }\end{array}$ & $\mathrm{R}^{2}$ & $\begin{array}{l}\mathrm{k}_{2} \\
\text { (c) }\end{array}$ & $\begin{array}{c}\mathrm{q}_{\mathrm{e}, \text { calc }} \\
\text { (b) }\end{array}$ & $\mathrm{R}^{2}$ & $\begin{array}{l}\text { ki } \\
\text { (d) }\end{array}$ & $\mathrm{X}$ & $\mathrm{R}^{2}$ & $\begin{array}{c}\alpha \\
\text { (e) }\end{array}$ & $\begin{array}{l}\beta \\
\text { (f) }\end{array}$ & $\mathrm{R}^{2}$ \\
\hline \multirow{3}{*}{0.011} & \multirow{3}{*}{10.735} & \multirow{3}{*}{0.9428} & \multirow{3}{*}{0.0017} & \multirow{3}{*}{18.78} & \multirow{3}{*}{0.9993} & 1.371 & 1.487 & 0.9686 & \multirow{3}{*}{1.66} & \multirow{3}{*}{0.28} & \multirow{3}{*}{0.9667} \\
\hline & & & & & & 0.349 & 11.256 & 0.9399 & & & \\
\hline & & & & & & 0.184 & 13.795 & 0.9941 & & & \\
\hline
\end{tabular}

Units: (a): $\min ^{-1}$; (b): $\mathrm{mg} \mathrm{g}^{-1} ;$ (c): $\mathrm{g} \mathrm{mg}^{-1} \min ^{-1} ;(\mathrm{d}): \mathrm{mg} \mathrm{g}^{-1} \min ^{0.5} ;$ (e): $\mathrm{mg} \mathrm{g}^{-1} \min ^{-1}$; (f): $\mathrm{g} \mathrm{mg}^{-1}$.
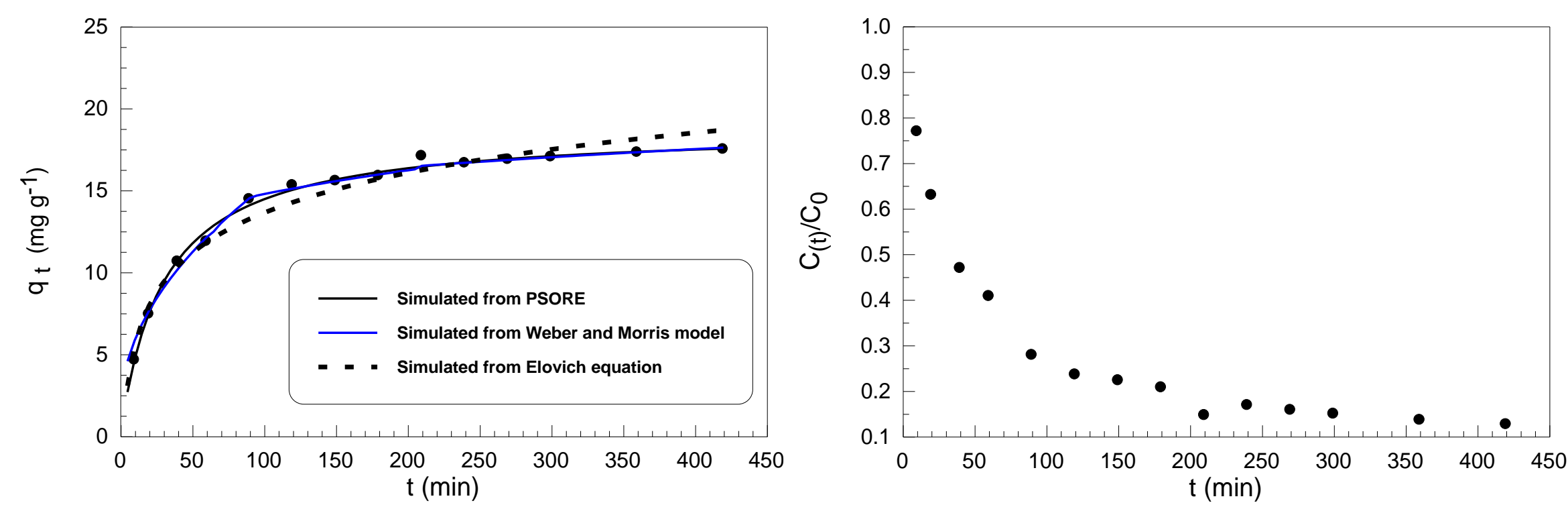

Fig. 3. The variation of adsorption capacity with adsorption time: (a) at $20 \mathrm{mg} \mathrm{L}^{-1}$ initial $\mathrm{Mg}(\mathrm{II})$ concentrations ( $\mathrm{T}=298 \mathrm{~K}, \mathrm{~W}=0.05 \mathrm{~g}, \mathrm{~V}=20 \mathrm{~mL}$ ). 

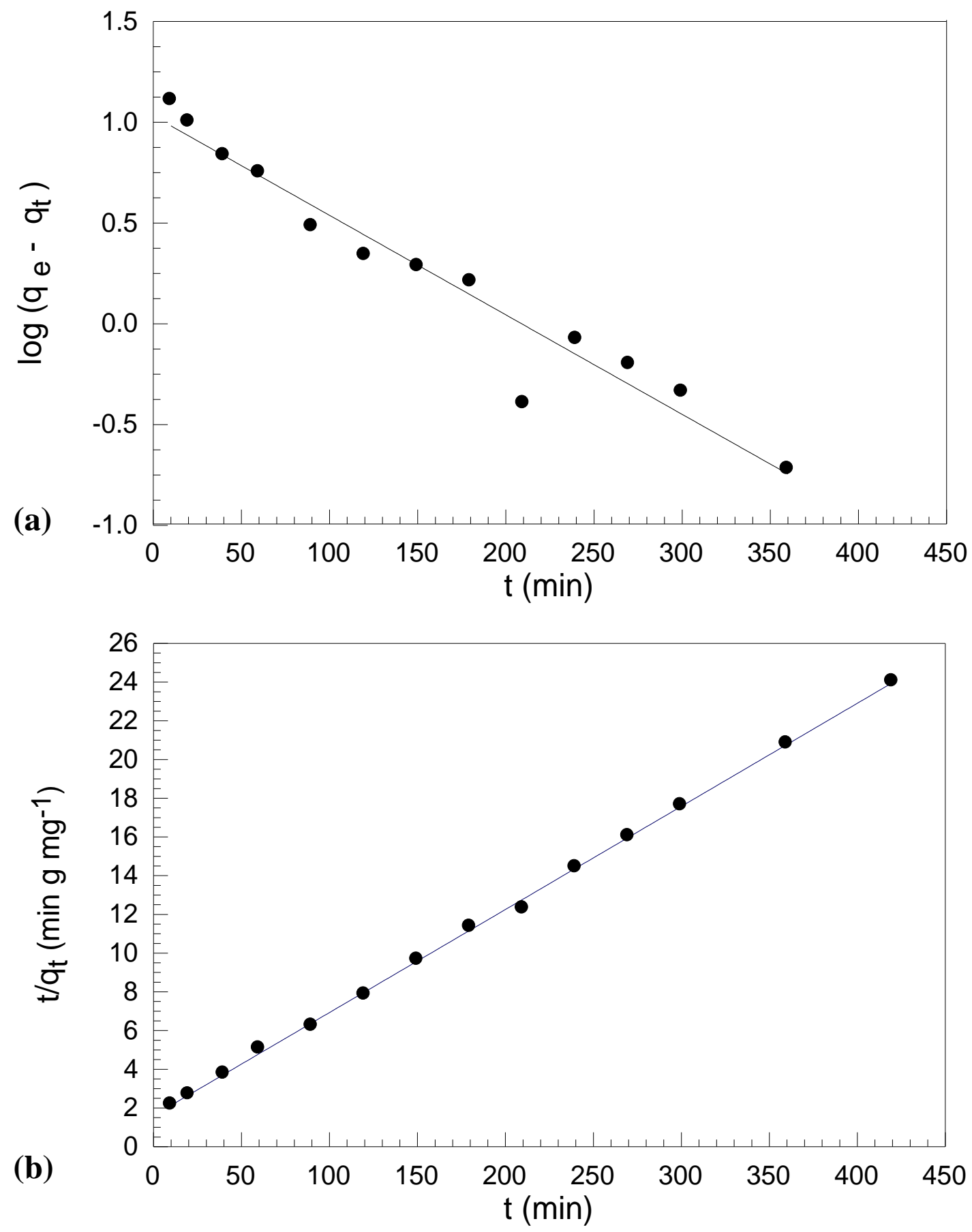

Fig. 4. (a) Pseudo-first-order kinetics for adsorption of $\mathrm{Mg}$ (II) ions onto the TF-TY sorbent at $298 \mathrm{~K}$. (b) Pseudo-second-order kinetics for adsorption of $20 \mathrm{mg} \mathrm{L}^{-1}$ initial of $\mathrm{Mg}$ (II) ions onto onto TF-TY at $298 \mathrm{~K}$. 
thiourea-formaldehyde polymer (Elwakeel et al., 2018) and removal of $\mathrm{Pb}(\mathrm{II}), \mathrm{Mn}(\mathrm{VII})$ and $\mathrm{Cr}(\mathrm{VI})$ using bentonite/thiourea-formaldehyde composite material (El-Korashy et al., 2016).

The intraparticle diffusion model provides a more comprehensive approach for defining of sorption mechanism, and the plot generally allows identifying different successive steps in the global process (Markovski et al., 2014). The Weber and Morris shows multi-linear sections (Fig. 5(a)), i.e., three linear sections (on the plot $\mathrm{q}_{\mathrm{t}} v s . \mathrm{t}^{0.5}$ ) with fast kinetics in first step followed by the gradual attainment of equilibrium, and a pseudo saturation plateau. The multi-linear plot does not pass through the origin suggesting that the resistance to intraparticle diffusion is not the sole rate-limiting step: other steps, e.g. resistance to film diffusion and/or reaction rate, are probably involved in the control of uptake kinetics (Table 2). The second section is characterized by a much lower kinetic rate and leads to a slow approach to equilibrium with the control by the resistance to intraparticle diffusion (into internal macroporous and mesoporous network). From the second region of the plot, which intra-particle diffusion related micro-pore diffusion is occurred; $\mathrm{Ki}_{2}, \mathrm{X}$ and $\mathrm{R}^{2}$ values were calculated and given in Table 2. A significant difference of $\mathrm{K}_{\mathrm{i}}$ values (Table 2) indicate the availability of the functional groups is primary controlled by diffusional transport through pores system in second and third steps, structure of the porous sorbent, i.e. pores network, consists from macropores which extends into particle interior and branched into tree like system of meso and micropores. The $\mathrm{Mg}$ (II) ions must diffuse through whole pore systems to reach total surface area within the particles, where the intraparticle diffusion, resistance due to diffusional transport inside pores, slow down overall process contributing to formation of time-dependent concentration gradient due to fast kinetic process at surface, until saturation of all available surface sites was achieved. X represents the boundary layer diffusion effects (external film resistance). As the value of $\mathrm{X}$ decreases the effect of boundary layer diffusion on the reaction rate decreases. The obtained values of $X$ (Table2) indicate that the boundary layer diffusion effect (external film resistance) has significant effect on the diffusion rate. The last step is very slow and represents only a few percentage of the total sorption: this phase can be associated to the resistance to diffusion in the microporous network of the sorbent. In addition the progressive saturation of available and accessible sorption sites influences the local equilibrium on the surface between surface sorption and desorption.

Elovich's equation is another rate equation based on the sorption capacity. In 1934 the kinetic law of chemisorptions was established though the work of Zeldowitsch (Zeldowitsch, 1934). It has commonly been called the Elovich equation. The values of $\alpha$ and $\beta$ were determined from the intercept and slope, respectively, of the linear plot of $\mathrm{q}_{\mathrm{t}} \mathrm{vs}$ lnt (Figure 5(b)). The value of $\alpha$ for the sorption of $\mathrm{Mg}$ (II) ions on the TF-TY sorbent is $1.66\left(\mathrm{mg} \mathrm{g}^{-1} \mathrm{~min}^{-1}\right)$. This value indicate that the initial sorption rate of $\mathrm{Mg}$ (II) ions is relatively high compared with the previous studies of El-Korashy et al. (ElKorashy et al., 2016). The high initial sorption rate of $\mathrm{Mg}(\mathrm{II})$ onto TF-TY sorbent may be attributed to the high concentration of active sites on the sorbent surface allowed for reacting with $\mathrm{Mg}(\mathrm{II})$ ions. The value of $\beta$ (desorption constant) is found to be $0.28 \mathrm{~g} \mathrm{mg}^{-1}$. 

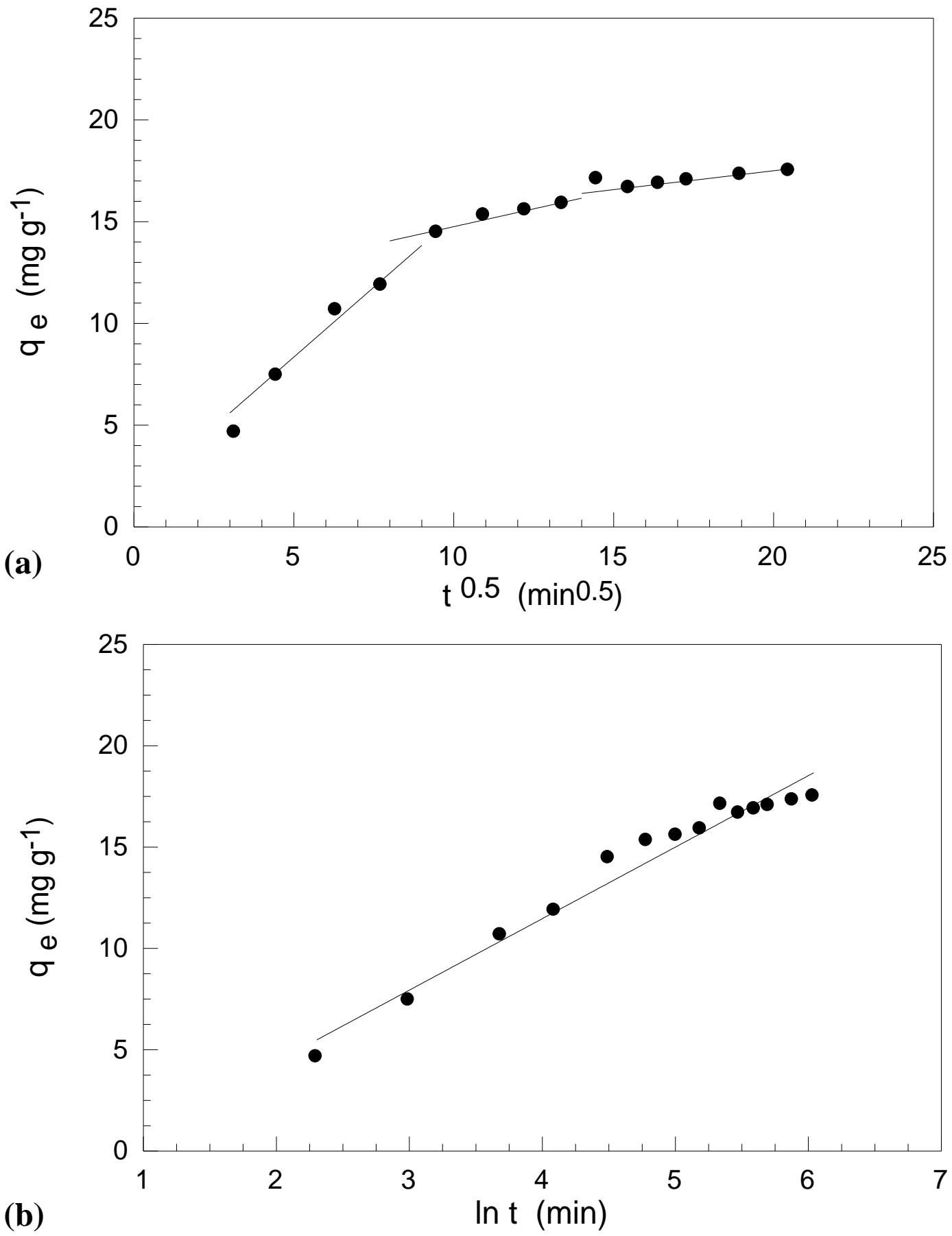

Fig. 5. (a) intraparticle diffusion model model for adsorption of $\mathrm{Mg}$ (II) ions onto TF-TY sorbent at $298 \mathrm{~K}$. (b) Pseudo-second-order kinetics for adsorption of $20 \mathrm{mg} \mathrm{L}^{-1}$ of $\mathrm{Mg}$ (II) ions onto onto TF-TY at $298 \mathrm{~K}$. 


\section{CONCLUSIONS}

The research shows that the TF-TY could be used to remove $\mathrm{Mg}$ (II) ions as cheap and available adsorbent. It was observed that the $\mathrm{pH}$ dependency of adsorption of $\mathrm{Mg}$ (II) was large. The amount of $\mathrm{Mg}$ (II) uptake increased with increasing of contact time. Their maximum adsorption capacity was $19.45 \mathrm{mg} \mathrm{g}^{-1}$. The adsorption kinetics was consistent with the pseudo-second-order kinetics models. It could be found that TF-TY has the good adsorption effect on $\mathrm{Mg}$ (II) ions, indicating that TF-TY could be used as the best an available material for water hardness reduction.

\section{ACKNOWLEDGMENTS}

This work was funded by the University of Jeddah (Saudi Arabia), under grant No. UJ-39-18-DR. The authors, therefore, acknowledge with thanks the University technical andfinancial support.

\section{CONFLICT OF INTEREST}

The authors declare that they have no known competing financial interests or personal relationships that could have influenced the work reported in this paper.

\section{REFERENCES}

Apell, J.N., Boyer, T.H., (2010) Combined ion exchange treatment for removal of dissolved organic matter and hardness. Water Res. 44, 2419-2430.

Boyd, C.E., Tucker, C.S., Somridhivej, B., (2016) Alkalinity and hardness: critical but elusive concepts in aquaculture. J. World Aquacult. Soc. 47 (1) 0.6-41.

Chen, Y., Lin, Y., Ho, S., Zhou, Y., Ren, N., (2018) Highly efficient adsorption of dyes by biochar derived from pigments-extracted macroalgae pyrolyzed at different temperature. Bioresource Technol. 259, 104-110.

Comstock, S.E.H., Boyer, T.H., (2014) Combined magnetic ion exchange and cation exchange for removal of DOC and hardness. Chem.Eng. J. 241, 366-375.

Dunlap, R.E., Mertig, A.G., (2014) Trends in public opinion toward environmental issues: 1965-1990. In: American Environmentalism. Taylor \& Francis, pp. 101-128.

El-Korashy S.A.., Elwakeel, K.Z., Abd El-Hafeiz, A., (2016) Fabrication of bentonite/thioureaformaldehyde composite material for $\mathrm{Pb}(\mathrm{II}), \mathrm{Mn}(\mathrm{VII})$ and $\mathrm{Cr}(\mathrm{VI})$ sorption: A combined basic study and industrial application, Journal of Cleaner Production 137, 40-50.

Elwakeel, K.Z., Al-Bogami, A.S., (2018) Influence of Mo(VI) immobilization and temperature on As $(\mathrm{V})$ sorption onto magnetic separable poly p-phenylenediamine-thiourea-formaldehyde polymer, Journal of hazardous materials 342, 335-346.

Hailu, Y., Tilahun, E., Brhane, A., Resky, H. , Sahu, O., (2019) Groundwater for Sustainable Development Ion exchanges process for calcium, magnesium and total hardness from ground water with natural zeolite, Groundwater for Sustainable Development 8, 457-467.

Harikishore, K.R.D., Vijayaraghavan, K., Kim, J.A., Yun, Y., (2017) Valorisation of post-sorption materials: Opportunities, strategies, and challenges. Adv. Colloid Interfac. 242, 35-58.

Harper, C., Harper, C.L., Snowden, M., 2017. Environment and Society: Human Perspectives on Environmental Issues. Routledge. 
Ho, Y.S., McKay, G., (1999) Pseudo-second order model for sorption processes. Process Biochem. 34, $451-465$.

Hounslow, A., (2018) Water Quality Data: Analysis and Interpretation. CRC press. Inglezakis, V.J., 2005. The concept of "capacity" in zeolite ion-exchange systems. J.of Coll. and Inter. Sci. 281 (1), 68-79.

Lagergren, S., (1898) About the theory of so-called adsorption of soluble substances. Kungliga Swenska Vet. 24, 1-39.

MacAdam, J., Jarvis, P., (2015) Water-formed scales and deposits: types, characteristics, and relevant industries. Min. Scal. and Dep. 6, 3-23.

Markovski, J.S., Markovic', D.D., Dokic', V.R., Mitric', M., Ristic', M.D., Onjia, A.E., Marinkovic', A.D., (2014) Arsenate adsorption on waste eggshell modified by goethite, $\alpha-\mathrm{MnO}_{2}$ and goethite/ $\alpha-\mathrm{MnO}_{2}$. Chem. Eng. J. 237, 430-442.

Rafatullah, M., Sulaiman, O., Hashim, R., Ahmad, A., (2010) Adsorption of Magnesium on low-cost adsorbents: a review. J. Hazard. Mater. 177, 70.

Smith, Y.R., Bhattacharyya, D., Willhard, T., Misra, M., (2006) Adsorption of aqueous rare earth elements using carbon black derived from recycled tires. Chem. Eng. J. 296, 102-111.

Teixeira, G.A., Vieira, W.F., Finzer, J.R.D., Malagoni, R.A., (2012) Citric acid crystallization process in dense phase using vibrated bed. J. Food Eng. 111, 458-465.

Tirkey, P., Bhattacharya, T., Chakraborty, S., Baraik, S., (2017) Assessment of groundwater quality and associated health risks: a case study of Ranchi city, Jharkhand, India. Groundwater for Sustainable Development 5, 85-100.

Weber, W.J., Morris, J.C., (1963) Kinetics of adsorption on carbon from solutions. J. Sanit. Eng. Div. ASCE. 89, 31-60.

Zeldowitsch, J., (1934) The catalytic oxidation of carbon monoxide on manganese dioxide. Acta. Physicochim. URS. 1, 364-449. 